\title{
Methodology of explanation of tactical and technical requirements for means of evacuation of weapons and military equipment
}

\author{
Volodymyr Dachkovskyi ${ }^{A}$
}

Received: June 6, 2020 | Revised: June 15, 2020 | Accepted: June 30, 2020

DOI: $10.33445 /$ sds.2020.10.3.9

\begin{abstract}
The main impact force of ground troops is the hard weapons and military equipment, that is why the loss of one of them is always painful for any army in the world The basic combat weapons and military equipment (high-precision samples of weapons and military equipment) are too expensive to destroy damaged vehicles or leave them on the battlefield. Realizing this, the special vehicles were created for the evacuation of this type of weapons and military equipment - armored repair and evacuation vehicle, which are designed to evacuate from the battlefield damaged and stuck tanks, infantry fighting vehicles, armored personnel carriers, selfpropelled artillery system and other units of equipment, even out of the probable enemy fire. Taking into account the analysis of the development of evacuation means which are in the service of the Armed Forces of Ukraine and the armed forces of the leading countries of the world, in this work the method of substantiation of tactical and technical requirements for means of evacuation of damaged weapons and military equipment is proposed. The essence of this method is to distribute the means of evacuation by mass and size, by type of mover, by the method of moving the damaged sample, by the level of application.

The formation of requirements is aimed at the transition of evacuation means and basic models of weapons and military equipment to unified basic platforms of the modular type. The implementation of these platforms will make it possible to install various types of special modules of evacuation means (material-handling, load-lifting, etc.) and modules of samples of weapons and special equipment.

The application of this metodology will provide an opportunity to obtain technical outlines of evacuation tools for different levels of the hierarchy, taking into account the scope of tasks assigned to them.
\end{abstract}

Key words: explanation of requirements, means of evacuation, tactical and technical requirements, weapons and military equipment.

\section{Introduction}

The task of high-quality restoration and timely return of damaged samples of weapons and military equipment (AME) to military formations (units) is entrusted to repair and restoration formations (units) that are part of the logistics system of the Armed Forces (AF) of Ukraine.

An important component of the recovery system of WME is the staffing of repair and restoration of military formations (units) with modern and effective means that operate in the middle of the system. This in turn affects the tactical and technical requirements which are put forward to means of evacuation of damaged samples of weapons and military equipment, the application of which depends on the efficiency of the subsystem for the evacuation of damaged samples of weapons and military equipment.

At present, depending on the place of application, evacuation means are used: at the tactical, operational, strategic levels. At the same

A The National Defence University of Ukraine named after Ivan Cherniakhovskyi, Kyiv, Ukraine, candidate of technical sciences, associate professor of the department of technical support, e-mail: 1903vova@ukr.net, ORCID: 0000-0003-1480-5021 
time, the tactical level involves the use of evacuation means at the battalion level and at the brigade level.

At the tactical level, means of evacuation are used directly during a military confrontation of military formations (units) with the enemy. They are used to evacuate damaged and stuck samples of WME to the nearest shelters or to the assembly points of damaged vehicles (APDV).

At the operational level, evacuation means are used directly during operations, usually on the brigades of the first echelon and on the assembly points of damaged vehicles of operational and tactical grouping of troops.

Strategic evacuation means are used to provide assistance to the forces and means of the operational level and to transport damaged samples of WME at the loading (unloading) station and to the repair enterprises of the defenseindustrial complex.

However, the existing fleet of evacuations means, which are in service with the Armed Forces of Ukraine, indicates that at all levels of the hierarchy are the same type of evacuation means of damaged samples of WME. The uniformity of which is not in unification but in production capabilities. That is, means of evacuation with the same production capabilities, the same degree of protection, etc. This approach to the staffing of different levels of the hierarchy of repair and recovery formations (units) with the same production capabilities of evacuation leads to inconsistencies in the need for protection of evacuation means at the tactical level, but at the strategic level, the level of protection of evacuation means may be lower than at the tactical level. At the strategic level, there is a need for means of evacuation with the ability to transport damaged samples of WME over long distances, and the main need is to reduce the nomenclature of basic platforms for both samples of WME and for evacuation means.

Therefore, taking into account the scope of tasks assigned to different levels of the hierarchy, taking into account the place of application of evacuation means, military formations (units) should be created and staffed with appropriate evacuation means with the appropriate level of security.

\section{Material and methods}

A number of works by both domestic and foreign scientists are devoted to the study of the formation of tactical and technical requirements for the means of evacuation and transportation of damaged samples of WME, in particular, in the work [1] the analysis of researches concerning scientific and technical support of development of armament of radio engineering armies and their combat and technical maintenance is carried out, and the publication [2] analyzes the means of evacuation, which are in service with the armed forces of the Russian Federation and the Republic of Belarus, and the main focus in this work is on the world-famous system multilift the literature [3] methods for solving problems of modernization of WME, synthesis of properties to assess the feasibility of modernization and search for rational solutions are considered, and the work [4] concerns the development, evaluation and improvement of the platform for $8 \times 8$ cars. Some aspects of this issue are presented in work [5], which is devoted to determining the directions of creation of basic wheeled chassis for the installation of weapons and for use of the chassis as a vehicle for transporting armored weapons and equipment, and in works [6-7] describes the development of a quantitative model the relationship between defense research and their costs. It was found that the cost of scientific work had a positive effect on the equipment received, which was studied. Some aspects of this issue are presented in work [8], which is devoted to the ease of use of manual vehicles, the work is aimed at summarizing previous studies on the basis of which ergonomic recommendations are proposed. Processing of this problem is also considered in the publication [9] which is devoted to the assessment and analysis of the level of vibration of armored vehicles and offers some preconditions for improving tracked 
platforms, and in work [10] various approaches to creating modular military vehicles, namely vehicles in the basis of which are assigned vertical modularity, horizontal modularity and distributed modularity. $t$ is determined that the application of the principle of modularity promotes adaptability, sustainability, and cost savings. In the literature [11] the issues of forming the type of military vehicles are considered, the main attention is focused on the creation of protected vehicles, and in work [12] the elements of substantiation of perspective armament system of type of armored forces are given, the methods used for substantiation of perspective armament system are listed, the stages concerning formation of a look of armament system are considered. Some issues of this problem are set out in [13], which analyzes the principles on which the system of logistics customer service is based and determines the sequence of actions for the formation of the logistics service system. An indepth study of this problem is reflected in the publication [13] which is aimed at substantiating the tactical and technical requirements for mobile repair equipment, and in work [14] is suggested the principles of construction accounting of robotic technical complexes of the
Land Forces, which are formed on the basis of tasks and also according to the requirements of using samples of WME. Some issues that affect the formulation of tactical and technical requirements for samples of weapons are considered in work [15] where the approach and basic measures for the creation on the chassis of crew samples of armored weapons and equipment of robotic complexes of heavy class are suggested, and in works [16-17] proposed an approach to formation of operational-strategic and operational-tactical requirements to the armament system, their components and the principles are considered, formation of the account of the perspective armament system.

Formulation of the purpose of the article.

Therefore, the purpose of the article is to develop a methodology for substantiating the tactical and technical requirements to the means of evacuation of WME, which operate at different levels of the hierarchy. Which will allow to take into account the level of the hierarchy of the subsystem of WME recovery, functional tasks, the scope of tasks. Which will determine the technical outlines of evacuation means for battalion, brigade, operational, strategic levels.

\section{Results and discussion}

Currently, the Armed Forces of Ukraine have caterpillars means of evacuation BREM-1, BREM "Lev", BREM -2, BREM -84 "Atlet", BREM -Ch, BTS5 and weeled BREM -7K, BTR-3BR, BREM -4, KETL, KT-L.

The BREM-1 armored repair and evacuation vehicle was created on the basis of T-72 family tanks, entered service in 1975 and designed to tow tanks weighing up to 50 tons [18]. Armored repair and evacuation vehicle BREM- 2 was adopted in 1966 [19] and created on the basis of the chassis of the infantry fighting vehicle BMP-1, has a high unification with BMP-1 and BMP-2 and has similar characteristics of mobility, security, survivability and ergonomics.

Armored repair and evacuation vehicle BREM "Athlete" is designed to prepare for evacuation and evacuation from the battlefield of damaged and stuck tanks, self-propelled artillery systems and other vehicles weighing up to 50 tons for their repair, excavation and welding [20]. This BREM was created on the basis of the chassis of the T-80UD tank in 2002 and is produced by the production association of the State Enterprise "Zavod im. Malysheva".

Armored repair and evacuation vehicle BREM7K, BTR-3BR, BREM-4 are designed for technical reconnaissance, towing faulty and damaged controlled and uncontrolled wheeled vehicles, loading work with moving cargo, removing stuck and sunked wheeled vehicles, transportation of spare parts and tools, etc. [21-23]. It is developed on the basis of the wheeled armored personnel carrier BTR-70Di - the wheeled, floating, armored car, with all driving wheels, equipped with two powerful diesel engines FPT "Iveco" (Euro-3).

Universal multi-purpose tank tractor BTS-5 is designed for technical reconnaissance on the 
battlefield, evacuation of damaged tanks from the area of enemy fire, retrieval of tanks that are stuck or sunk, loading, excavation, welding, etc. [24].

For evacuation of automobile equipment (AE) the Armed Forces of Ukraine are armed with wheeled evacuation devices KT-L, KET-L which purpose is similar to caterpillar EZ but they concern only AE [25-26].

Tractors with semi-trailers are used to transport WME over long distances [27].

Armored repair and evacuation vehicle BREM - $L$ is in service with the Russian Federation and is designed to evacuate damaged or defective light combat vehicles by weight from under enemy fire, to assist crews in repairing and maintenance of WME samples in the field. Created on the basis of the chassis of the infantry fighting vehicle BMP-3 [28].

To perform the most complex and difficult work in the US Army use an upgraded BREM M88A2 Hercules. HERCULES (Heavy Equipment Recovery Combat Utility Lift and Evacuation System). This machine was developed by BowenMcLaughlin-York (BMY) company in the late 1950s. In 1977, this BREM was modernized [29]. All of them are based on the original version of the machine, built on the basis of tanks M48 i M60 Patton. On the M88A2 HERCULES version.

BREM WZT-3 and WZT-4 are in service with the Polish Army, which is built on the basis of PT-91. This machine is an adaptation of the Soviet tank $\mathrm{T}-72 \mathrm{M} 1$, which is manufactured in Poland [30].

BREM Buffalo, built on the basis of the world's successful main battle tank Leopard-2. BREM Bergepanzer 3 Büffel or BPZ 3 was created by order of the armed forces of Germany and the Netherlands. This machine is designed for evacuation from the battlefield of damaged and stuck tanks and other combat equipment, as well as performing various repairs in the field [31].

Currently, the British Army BREM, which is based on the chassis of the tank "Challenger-1" and which remains in service, is CARRV Challenger Armored Repair and Recovery Vehicle. This BREM completely repeats "Challenger-1" with its engine, running gear, lower part of the case and a number of aggregates and systems [32].

Armored repair and evacuation vehicle $A B 1$
Monjed P2 developed by KADDB, BREM was created on the basis of the chassis of the American tank M60A1 in close cooperation with specialists of the Jordanian Armed Forces and is designed to evacuate damaged military equipment and assist crews in its repair in the field [33].

Given the considered means of evacuation, which are in the service of the Armed Forces of Ukraine and the leading countries of the world, it can be concluded that the means of evacuation are usually created on the basis of basic samples of WME, which are in service with the relevant Armed Forces. However, the analysis of the type of evacuation means, which are in the service of repair and restoration military formations (units) of the Armed Forces of Ukraine and those that are allowed to operate, indicates their wide nomenclature. That is, some means of evacuation duplicate the functions of others in their capabilities, tactical and technical characteristics, etc. The same tendency to increase the nomenclature is observed with samples of WME that were in service with the Armed Forces of Ukraine until 2014 and allowed to operate in the Armed Forces of Ukraine after the start of hostilities in eastern Ukraine [34]. It is clear that in order to protect the territorial integrity of Ukraine from the aggressive actions of the Russian Federation in eastern Ukraine, there was an urgent need for effective, modern models of WME. However, the increase in the nomenclature of weapons samples leads to an increase in the load on the logistics system of the Armed Forces of Ukraine, namely on the subsystem of WME recovery, provision of material and technical means, etc. At present, there is a need to revise the existing approaches to determining the need and nomenclature of WME samples, respectively, and the nomenclature of evacuation of damaged samples of WME.

The formation of tactical and technical requirements (TTR) for evacuation means is carried out in accordance with the operational and tactical requirements for all samples of WME [35]. The initial data influencing formation of tactical and technical requirements are offered in work [36].

Given the analysis of the development of WME in Ukraine and leading countries, the specifics of 
their use - evacuation devices in general can be classified by mass and size or traction on the hook of the evacuation vehicle (heavy, medium, light), by type of engine (wheeled, tracked) , according to the method of moving the damaged sample of WME (towing, transportation) and in accordance with the conditions of use (means of evacuation that will operate at the tactical, operational, strategic levels or means of evacuation that operate at different boundaries of logistics).

Therefore, all these circumstances prompt the need to create modern domestic highly efficient means of evacuation, which would ensure the effective evacuation of damaged samples of WME.

At the first stage there is a need to find new and effective ways to create multifunctional platforms. One of the ways to solve this problem can be to create basic platforms built on a modular basis $[37,38]$.

These base platforms must be able to accommodate the control system module, propulsion system module, transmission module, chassis module, in addition, the platform housing must contain standardized cells for mounting these modules to ensure rapid replacement in case of failure. Also, these platforms must provide the ability to install various types of special equipment, etc.

And at the second stage there is a need to create standardized special equipment for these platforms, which would be installed on these platforms depending on the specifics of application. That is, lifting and transport modules, lifting modules, fire modules, modules for transportation of material and technical means and special modules for performing tasks of troops and services [39, 40].

The special requirements for base platforms include:

high level of unification in order to reduce the range of spare parts;

compliance of the design with specific operating conditions, requirements of state standards and regulations;

transportability - the suitability of structures for transportation on railway platforms, ships and aircraft;

high operational and tactical mobility - the ability to carry out long marches at high speeds, passability on dirt roads and off-roads, high stability and maneuverability (controllability), adaptability to operation in different climatic regions, day and night;

reliability and survivability of structures, including resistance to damage by high-precision weapons and other types of weapons [41, 42];

protection of crew and cargo, personnel from penetrating radiation, radioactive dust, chemical and biological agents, light radiation, shock wave, as well as from fragments and bullets [43];

convenience and ease of operation;

safety of the driver (mechanic-driver) in columns with high speeds of movement;

ow fatigue of the driver (mechanic-driver) and personnel, safety of MTZ transported or special equipment mounted on the platform;

simplicity and expediency of constructions from the point of view of their maintenance and repair in field conditions;

adaptability of base platforms to evacuation;

high technical and economic indicators of structures in production and operation.

The values of each of these requirements for different groups of base platforms are different. Thus, for the basic platforms of the strategic level, the defining requirements are the efficiency of the structure in production and operation, high productivity during transportation, towing of damaged samples of weapons by highways; for basic platforms of operational level - high operational and tactical mobility and reliability at work both on roads or column ways, and out of roads; for basic platforms of tactical level - high passability and reliability of work off the roads, directly on the battlefield, protection of the crew from means of defeat of the enemy, etc.

Consider the main special requirements for the basic platforms of evacuation vehicles. Note that the numerical data included in these requirements, if they are standardized, are indicative. When applying them to the design of base platforms, they must be specified accordingly. In addition, the development of technology over time will make adjustments to this data.

An important weight characteristic of base platforms is the load capacity factor, which is the 
ratio of the nominal load capacity of the base platform $G_{r}$ to its weight in the equipped state $G_{s}$

$$
K_{r}=\frac{G_{r}}{G_{s}}
$$

For wheeled base platforms, the type of tire and their size are determined based on the maximum values of loads, $G_{k_{\text {Max }}}$, on the wheels, using the data for which level of hierarchy will be assigned to this base platform. The axle load shall not exceed the maximum permissible values determined by the operating conditions of the evacuation means on the different roads.

The load on the wheel is determined by the ratio

$$
G_{k}=\frac{G}{n}
$$

where $G$ - full weight of the base platform;

$n$-the number of axes of the base platform.

Along with the support passability for wheeled evacuation vehicles, the indicators of profile passability are no less important, which are mainly determined by such geometrical parameters of the base platform as the magnitude and angles of the ground clearance.

The average value of the wheel pressure on the ground is determined by the dependence

$$
q=\frac{G_{k}}{F_{k}}
$$

where $q$-the average value of the pressure of the wheel on the bearing surface, $P a$;

$G_{k}$ - vertical load on the wheel, $N$;

$F_{k}$ - the contact area of the wheel with a completely rigid surface, $\mathrm{m}^{2}$.

The contact area of the wheel with an absolutely rigid surface is determined by the dependence

$$
F_{k}=\frac{\pi}{4} a_{k} b_{k}
$$

where $a_{k}$ and $b_{k}$ - the length and width of the imprint of the contour area on a rigid basis $(\mathrm{m})$.

$$
\begin{aligned}
& a_{k}=C_{3} \sqrt{D f_{c m} f_{c m}^{2},} \\
& b_{k}=2 \sqrt{2 R_{n p} f_{c m} f_{c m}^{2}},
\end{aligned}
$$

where $f_{c m}$ - static deflection of the tire under load $G_{k}, \mathrm{~m}$;

$$
\begin{aligned}
& R_{n p} \text { - the given radius of the tire, } \mathrm{m} ; \\
& C_{3} \text {-correction factor. }
\end{aligned}
$$

The given radius of the tire $R_{n p}$ and correction factor $C_{3}$ is determined from dependencies

$$
\begin{gathered}
R_{n p}=\frac{D+H}{2,5}, \\
C_{3}=\frac{20,5}{11,9\left|\frac{D}{B}-\frac{|n-9|}{2}-3\right|}
\end{gathered}
$$

where $n$-norm for tire layers;

$D, H, B$ - respectively diameter, height and width of the tire profile, $m$.

The maximum wheel pressure on the support surface is determined by the dependence

$$
q_{\max }=\frac{K_{2} q_{c p}}{K_{1}},
$$

where $K_{1}$ - coefficient that depends on the outer diameter of the tire;

$K_{2}$ - the coefficient of longitudinal nonuniformity of pressure distribution over the area of contact of the tire with the bearing surface;

$q_{c p}$ - the average value of the pressure of the wheel on the bearing surface, $P a$.

Static deflection of the tire can be determined experimentally or calculated according to the dependence, which is given in work [36]. It is also necessary to take into account what will be the depth of the track with a single load on the ground of the base wheel platform.

To determine the basic parameters of crawler platforms should be known: the total weight of the base platform, the maximum speed and road conditions, i.e. the actual allowable average pressure of the caterpillar on the road surface.

The order of calculations provides: the choice of the type of transmission and traction calculations with the definition of the gear ratio in different gears. Based on the allowable operating conditions (adhesion coefficients of the mover to the road, resistance to rotation and translational motion of the platform), based on the need to ensure the coupling properties of the crawler mover, determine the value of "base ratio", the 
allowable value of the average pressure of caterpillars on the ground, diameter of support rollers, etc [36].

The required power of the propulsion system module can be determined on the basis of the equation of traction balance, which has the form

$$
N_{e \max }=\left(f G+R_{B}\right) \frac{V_{\max }}{\eta_{t p} \eta_{m y} \eta_{2 \partial}}
$$

where $N_{\text {smax }}$ - maximum effective power of the propulsion system module, $\mathrm{kW}$;

$V_{\text {max }}-$ maximum speed of the base platform;

$f$ - coefficient of road resistance (rolling resistance on straight road);

$G$ - full weight of the base platform, kN;

$R_{B}$-the force of air resistance when moving at maximum speed,

$\eta_{c y}, \eta_{m p}, \eta_{p}$ - efficiency of the propulsion system module in the mode of the maximum speed, transmission and the mover accordingly.

Determination of the force of air resistance during movement is given in [36].

Stability on overturning of base platforms is one of the main requirements.

Determination of the load on the boards from the modules with the condition of equilibrium of the system follows

$$
\sum M_{o}=0 \text {, that is } \sum G_{i} y_{i}-R_{n p} B=0,
$$

where $G_{i}$ - gravity of the $i$ module mounted on the base platform, $\mathrm{N}$;

$m$ - mass of the $i$ module, $\mathrm{kg}$;

$g$-acceleration of gravity, $\boldsymbol{M} / \mathrm{c}^{2}$;

$y_{i}$ - the distance from the center of weight $i$ of aggregate to the coordinate axes, $\mathrm{mm}$;

$R_{n p}$ - the reaction of the soil, which is equal to the load on the mover of the starboard side, $\mathrm{N}$;

$$
B \text {-track, } \mathrm{m} \text {. }
$$

The load from the equipment on the left side can be determined

$$
R_{n p}=\frac{\sum G_{i} y_{i}}{B},
$$

Accordingly, the load from the equipment on the left side will be

$$
R_{l}=\sum G_{i}-R_{n p},
$$

The load on the axles is determined from the equilibrium condition of the system

$$
\sum M_{o}=0 \text {, that is } \sum G_{i} y_{i} \quad R_{3} L=0,
$$

where $x_{i}$ - the distance from the center of weight of the $i$ module to the coordinate axis, $\mathrm{mm}$;

$R_{3}$ - reaction from the support surface of the rear wheels, $\mathrm{N}$;

$L$ - platform base, $\mathrm{mm}$;

Accordingly, the reaction to the front wheels

$$
R_{n}=\sum G_{i}-R_{3},
$$

The transverse coordinate of the center of weight of the base platform is determined from the expression

$$
y=\frac{R_{n p} B}{G_{0}}
$$

The sum of the moments of all forces relative to the contact pads of the front wheels is determined by

$$
\sum M_{0}=\Pi_{0} h_{g},
$$

where $h_{g}$ - the height of the center of weight of the base platform, $\mathrm{mm}$.

Taking into account that

$$
\sum M_{0}=\sum G_{i} Z_{i}+G_{M} h,
$$

where $Z_{i}$ - height of the center of weight $i$ of the module, $\mathrm{mm}$;

$G$ - the weight of the module with the base platform, $\mathrm{N}$;

$m$ - the mass of the module and the base platform, kg;

$h$-height of the center of gravity, $\mathrm{mm}$.

Due to the fact that the loads on the chassis are caused by the action of gravity, the mass on board and the axis is determined by the formula

$$
m=\frac{G}{g}
$$

where $G$ - effective load force, kg. 


\section{Conclusions}

Thus, in the work on the basis of the conducted analysis of the development of evacuation means in the Armed Forces of Ukraine and the leading countries of the world the requirements to the basic wheel and caterpillar platforms are determined. The essence of the technique is to determine the requirements for the mover (wheel, caterpillar), the propulsion system module, to determine the parameters of the stability of the base platforms for overturning, and other requirements for the modules of the base platform.

The set of indicators listed in the tactical and technical requirements determines the effectiveness of promising means of evacuation and aims their continuous improvement.

In the future there is a need to determine the tactical and technical requirements for modules of special equipment of evacuation vehicles, which will operate at different levels of the hierarchy.

6. Middleton A., Bowns S., Hartley K., Reid J. The Effect of Defence R\&D on Military Equipment Quality, Defence and Peace Economics, Taylor \& Francis Journals, 2006. vol. 17(2), p. 117-139. DOI: $10.1080 / 10242690600636869$

7. M. Brzoska Trends in Global Military and Civilian Research and Development (R\&D) and their Changing Interface. [Electronic source]: Access mode:

http://ifsh.de/pdf/aktuelles/india_brzoska.pdf

8. Jung, M.C., Haight, J.M., Freivalds, A. Pushing and pulling carts and two-wheeled hand trucks. International Journal of Industrial Ergonomics, (2005). №35(1), p. 79-89. https://doi.org/10.1016/j.ergon.2004.08.006

9. Kaegen Seow Ee Hung, Tan Teck Chuan, Ang Liang Ann Reducing Vibration in Armored Tracked Vehicles. [Electronic source]: Access mode: https://www.dsta.gov.sg/docs/defaultsource/dsta-about/reducing-vibration-inarmou red-tracked-vehicles.pdf?sfvrsn=2

10. Jean M. Dasch and David J. Gorsich Survey of Modular Military Vehicles: benefits and burdens. Defense Acquisition research journal. A Publication of the Defense Acquisition University. 2016. Vol. 23 No. 1. p. 2-27.

11. Shevchenko A. A. Military vehicles are an important component of the defense industry of the Russian Federation. [Electronic source]: Access mode: http://federalbook.ru/files/OPK/Soderjanie/O PK-11/III/Shevchenko.pdf

12. Demidov B.A. Velichko A.F. Khmelevskaya O.A. Elements of the methodology of substantiation 
of directions of development and formation of appearance of perspective system of armament of a kind of armed forces of the state. Control, navigation and communication systems. 2010. Vip. 3 (15). with. 187-194.

13. Dachkovskyi V. Methodology of justification of tactical and technical requirements for movable means of repairing arms and military equipment. Social development \& Security. 2019. № 9(6), 86-101. DOI: http://doi.org/10.33445/ sds.2019.9.6.7

14. Rudianov N. A. Khrushchev V.S. Substantiation of the appearance of combat and supporting robotic systems of the Ground Forces. Electronic Resource [Access Mode] http://engjournal.ru/articles/937/937.pdf

15. Chepkov, I.B. Dovhopolyi, A.S. Husliakov, O.M. Conceptual bases of creation of domestic shock-reconnaissance ground robotic complexes of a heavy class. Weapons and military equipment. 2019. №3 (23). pp. 16-25.

16. Grib, D.A. Demidov, B.A. Khmelevskaya O.A. Principles and aspects of the methodological approach to the formation of operationalstrategic and operational-tactical requirements for the promising armament system of the armed forces of the state and its structural components. Science and technology of the Air Force of the Armed Forces of Ukraine. 2013. № 2 (11). pp. 29-34.

17. Grib, D.A. Demidov, B.A. Naumenko, M.V. System-conceptual bases and elements of methodology of formation of operative-tactical and tactical-technical requirements shown to perspective samples of armament and military equipment and models which are modernized. Weapons systems and military equipment. 2009. №2 (18). pp. 65-73.

18. Armored recovery vehicle BREM-1. Technical description. Moscow: Military Publishing. 1984. p. 132.

19. Lepeshinsky, I.Yu. Kostin, K.V. Anufriev, E.V. Pogodaev, V.P. Varlakov, P.M. Munin, V.A. Chikirev, O.I. Kryukov, K.S. Kolobov A.A. Repair of armored vehicles. Omsk Publishing house OmGTU. 2011. p. 320.

20. Armored repair and evacuation vehicle BREM "Athlete". [Electronic source]: Access mode: https://morozov.com.ua/ua/bronetankovaya- tehnika-i-vooruzhenie/boevye-bronirovannyemashiny/razrabotki/atlet/

21. Armored repair and evacuation vehicle BREM -7K. [Electronic source]: Access mode: https://uk.wikipedia.org/wiki/\%D0\%91\%D0\%A 0\%D0\%95\% D0\%9C-7\%D0\%9A

22. Armored repair and evacuation vehicle BTR3BR. [Electronic source]: Access mode: https://zhbtz.com/produkc-ja-ta-poslugi/ produkc-ja-v-iskovogo-priznachennja/kol-snabronetehn-ka/btr-3br.html

23. Armored repair and evacuation vehicle BREM -4. [Electronic source]: Access mode: https://morozov.com.ua/ua/bronetankovayatehnika-i-vooruzhenie bronirovannyemashiny/razrabotki /btr-4/

24. Kuznetsov, I.B. Yaroshenko A.V. Ovcharenko, I.V. Dachkovskyi V.O. Application of units and military formations of technical support. Part II: Repair and restoration military unit: textbook. way. Kyiv: NUOU them. Ivan Chernyakhovsky, 2018. $80 \mathrm{p}$.

25. Tow trucks of damaged cars. Textbook. Minsk. BNTU. 2010. p. 128

26. Evacuation of motor vehicles. Guidance. Part 1. Technical bases and means of evacuation of cars. The order of evacuation works. Moscow: Military Publishing House. 1985. p. 240.

27. Dachkovskyi, V. O. Ovcharenko, I. V. Yaroshenko O.V. Fundamentals of evacuation of weapons and military equipment. Kyiv: NUOU, 2017. $180 \mathrm{p}$.

28. Gubin S.G. Mobile means of maintenance and repair. Novosibirsk SGGA. 2009. 100.

29. Armored repair and evacuation vehicle $M 88 A 2$ Hercules. HERCULES (Heavy Equipment Recovery Combat Utility Lift and Evacuation System). [Electronic source]: Access mode: http://www.army-guide.com/rus/product 2036.html

30. Armored repair and evacuation vehicle WZT-3 and WZT-4. [Electronic source]: Access mode: https://warriors. fandom.com/ru/wiki/WZT3M

31. Armored repair and evacuation vehicle БPEM Buffalo, Bergepanzer 3 Büffel. [Electronic source]: Access mode: http://factmil.com/stuff/armija/inzhenernaja_ tekhnika/bpz_3_buffel_buffalo/57-1-0-180 
32. Armored repair and evacuation vehicle CARRV - Challenger Armoured Repair and Recovery Vehicle. [Electronic source]: Access mode: http://parm. mybb.ru/viewtopic.php?id=835

33. Armored repair and evacuation vehicle $A B 1$ Monjed P2 [Electronic source]: Access mode: http://bodyguards.com.ua/watchman/3949brem-ab1-monjed-p2-yordanya.html.

34. Dachkovskyi V.O. Ovcharenko I.V. Analysis of armoured combat vehicles. Modern Information Technologies in the Sphere of Security and Defence, 2016. № 2(26) C. 127 132.

35. On approval of the instruction on formation of operative-strategic, operative-tactical and general requirements to armament and military equipment of the Armed Forces of Ukraine. Order of the General Staff of the Armed Forces of Ukraine from 24.05.2016 № 213

36. Research of the state and prospects of development of mobile means of maintenance, repair and evacuation of weapons and military equipment of the Land Forces: Report on NDR code "Repair"; dir. S.A. Kopashinsky Kyiv: 2017. 217 p.

37. Patent. 133641 Ukraine, MPK (2009) F41 H 7/00. Basic caterpillar platform of modular type / Dachkovskyi V. O., Ovcharenko I. V., Yaroshenko O. V., Sampir O. M., Kurovskaya T. Yu. - applicant and patent holder Dachkovskyi V.O. - № u201812482; application. 12/17/2018; publ. 04/10/2019; Bull. № 7.

38. Patent. 134972 Ukraine, MPK (2009)) F41 H 7/00. Basic wheel platform of modular type / Dachkovskyi V.O. - applicant and patent holder Dachkovskyi VO - № u2019 00225; application.
09/01/2019; publ. 06/10/2019; Bull. № $11 / 2019$.

39. Patent. 128878 Ukraine, MPK (2017) B60D $1 / 00$. Lifting and transport device / Dachkovskyi V.O. Ovcharenko I.V., Yaroshenko O.V.; applicant and patent holder National University of Defense of Ukraine. Ivan Chernyakhovsky № u201804262; application. 04/18/2018; publ. 10/10/2018; Bull. № 19.

40. Patent. 98552 Ukraine, MPK (2009) F42 B $23 / 00,39 / 26$. Complex of detection and defeat of the purposes / Dachkovskyi V.O.; - applicant and patent holder Dachkovskyi V.O. - № u201413542; application. 16.12.2014; publ. 27.04.2015; Bull. № 8.

41. Dachkovskyi, V.O. Method of determination of survival characteristics of weapons and military equipment. Social development \& Security. 2020. №10 (1), 18 - 24. DOI: https://doi.org/10.33445/sds.2020.10.1.3.

42. Dachkovskyi V.O. Vorobyov O.M., Grozovsky R.I. Methodical approach to determining the quality indicators of weapons and military equipment repair. Problems of quality of defense products: organizational, technical and financial and economic aspects. II All-Ukrainian scientific-practical conference. May 26, 2020. Kyiv, 2020 p. 32-48.

43. Kurtseitov, T. Dachkovskyi,V. Kizyak, Y. Uhrynovych, O. Experimental study of stability of base wheel platforms to the influence of explosive objects. Natural, Mathematical and Technical science NaMaTech - 2018, Held in Budapest on 16th of December 2018. https://doi.org/10.31174/SEND-NT2018186VI22-15 